\title{
Infusion Site Extravasation
}

National Cancer Institute

\section{Source}

National Cancer Institute. Infusion Site Extravasation. NCI Thesaurus. Code C78362.

Leakage of a pharmacologic or a biological substance from the infusion site into the surrounding tissue. Signs and symptoms include induration, erythema, swelling, burning sensation, and pain at the infusion site. 